Research Article

\title{
Monitoring of Antimicrobial Susceptibility of Bacteria Isolated from Poultry Farms from 2014 to 2018
}

\author{
Engy Ahmed Hamed (D), May Fathy Abdelaty $\left(\mathbb{D}\right.$, Hend Karam Sorour ${ }^{D}$, Heba Roshdy ${ }^{D}$, \\ Mona Aly Abdelhalim AbdelRahman $(\mathbb{D}$, Ola Magdy, Waleed Abdelfatah. Ibrahim, \\ Ahmed Sayed, Hytham Mohamed, Mohammed Iraqi Youssef, Wafaa Mohamed Hassan, \\ and Heba Badr iD
}

Reference Laboratory for Veterinary Quality Control on Poultry Production, Animal Health Research Institute, Agricultural Research Center (ARC), Nadi El-Seid Street, Dokki P.O. Box 246, Giza 12618, Egypt

Correspondence should be addressed to Engy Ahmed Hamed; drengyahmed_2020@yahoo.com

Received 15 May 2021; Accepted 25 August 2021; Published 10 September 2021

Academic Editor: Nora Mestorino

Copyright (C) 2021 Engy Ahmed Hamed et al. This is an open access article distributed under the Creative Commons Attribution License, which permits unrestricted use, distribution, and reproduction in any medium, provided the original work is properly cited.

\begin{abstract}
The current situation of antibiotic resistance of most bacterial pathogens was a threat to the poultry and public health with increasing economic losses. Regarding this problem, monitoring of the circulating microorganisms occurred with the antibiotic resistance profile. A total of 657 different samples from internal organs (liver, heart, lung, and yolk) and paper-lining chick boxes were collected from native chicken farms which were submitted to the Reference Laboratory for Veterinary Quality Control on Poultry Production in the period from 2014 to 2018 for the detection of Salmonella, Escherichia coli (E. coli), and Staphylococcus. The bacterial isolates were tested for their antimicrobial susceptibility by disk diffusion technique. Salmonella was isolated from 128 out of 657 (19.5\%), E. coli was isolated from 496 out of 657 (75.5\%), and Staphylococcus species was isolated from 497 out of $657(75.6 \%)$. All Salmonella positive samples were examined for antibiotic resistance against 10 different antibiotics, and the highest percentage all over the five years was against penicillin, ampicillin, and tetracycline. All E. coli positive samples were examined for antibiotic resistance against 14 different antibiotics, and the highest percentage all over the five years was with ampicillin, tetracycline, norfloxacin, streptomycin, and danofloxacin. All Staphylococcus positive sample species were examined for antibiotic resistance against 14 different antibiotics, and the highest percentage of resistance all over the five years was shown with tetracycline, streptomycin, ampicillin, and nalidixic acid.
\end{abstract}

\section{Introduction}

Poultry is one of the major sources of protein for humans, and in last year, there were new breeds that could reach the growth weight in a short period maybe six weeks or less. Therefore, when human eats this poultry meat, it will affect the normal microflora in human intestinal tract and also may lead to development of resistance to these antibiotics in the human body [1].

There are many mechanisms of generation of antibiotic resistance genes in bacteria. First one occurred in producer bacteria which generate self-resistant genes to protect themselves from their own antibiotics; this mechanism is called the self-defense mechanism. Misuse of antibiotics in treatment or as growth promoters is one of the important causes of mutation in genes of pathogenic bacteria, and the generation of new strains of resistance bacteria to these antibiotics may also have an effect on commensal bacteria which present normally in the gastrointestinal tract and produce antibiotic resistance genes which are transferred to the pathogenic bacteria by plasmids through (horizontal gene transfer) which lead to a generation of a new pathogenic antibiotics resistant strain. Another way for the production of antibiotic bacterial resistant strains occurs outside 
the host body (in the soil) via horizontal gene transfer through transferring the resistance gene from the producer bacteria or from the nonproducer bacteria (environmental bacteria) to pathogenic strains through the plasmid or phage [2]. Antibiotic-resistant bacteria in poultry farms lead to significant economic losses by spending a lot of money on the treatment and disinfection of poultry houses after infection. Therefore, you must stop abusing antibiotics, and use antibiotics as a treatment only after performing an antibiotic sensitivity test in vitro to determine effective antibiotic therapy, and give antibiotics in the recommended dose, period, and follow the withdrawal period list for preventing its effect on human health [3].

Salmonellosis, colibacillosis, and staphylococcosis are major diseases that affect poultry farms and cause a high economic loss due to high mortality and morbidity rates, cause drop in egg production, and affect in feed conversion and growth rates. All of them cause septicemic lesions, and we can differentiate between them through postmortem inspection. Salmonella causes unabsorbed yolk sac in young chicks and focal necrosis in the mucosa of the small intestine, and sometimes, with caseated material in cecal cores, it affects oviducts and ovaries in adult chickens. E. coli causes omphalitis in young chicks and salpingitis, and the respiratory form causes the swollen head syndrome and airsacculitis. Staphylococcus causes osteomyelitis and arthritis [4-6].

In developing countries, the farmers use antimicrobials in subtherapeutic doses for prophylaxis or as growth promoters in poultry farms. All the aforementioned cases of antibiotic misuse affect bacterial response to these antibiotics as treatment and development of multidrugresistant (MDR) bacteria which may be transmitted to humans indirectly by the consumption of poultry or poultry byproducts $[7,8]$. The aim of this study is to monitor the antibiotic resistance profile of Salmonella, E. coli, and Staphylococcus isolated from poultry farms during the period from 2014 to 2018.

\section{Materials and Methods}

2.1. Sampling. A total of 657 different samples from internal organs (liver, heart, lung, and yolk) and paperlining chick boxes were collected from native chicken farms which were submitted to the Reference Laboratory for Veterinary Quality Control on Poultry Production (RLQP) from 2014 to 2018.

This study was done on different ages including apparently healthy and diseased chickens which showed, in postmortem examination, different criteria such as congestion, necrosis in the liver, bronzy liver, congestion in the heart, congestion in the lung, pneumonia, pericarditis, perihepatitis, omphalitis, typhlitis, and enlarged ceca.

Pooled organ samples were collected such as the liver, heart, and lung, and on the other side, the yolk sac and paper-lining chick boxes or two ceca were collected separately under aseptic conditions according to Middleton et al. [9]. All samples were examined bacteriologically for the presence of Salmonella, E. coli, and Staphylococcus.

\subsection{Bacteriological Examination}

Salmonella isolation and identification were done according to standard methods $[10,11]$

E. coli isolation was carried according to Lee et al. [12]

Staphylococcus isolation was done according to standard methods [13]

2.3. Antimicrobial Sensitivity Test. The antimicrobial sensitivity test of all isolated Salmonella, E. coli, and Staphylococcus strains was conducted according to Koneman et al. [14] by the disc diffusion method, and different antibiotic discs were used such as ampicillin Amp10, chloramphenicol C30, ciprofloxacin CIP5, colistin sulfate CT25, danofloxacin DX, doxycycline Do30, enrofloxacin ENR5, erythromycin E15, fosfomycin FOS-200, levofloxacin LEV-5, nalidixic acid NA30, norfloxacin NOR10, nitrofurantoin F300, penicillin P10, streptomycin S10, tetracycline T30, and trimethoprimsulfamethoxazole 25 SXT; Oxoid. The results were interpreted according to the Clinical and Laboratory Standards Institute [15].

\section{Results}

3.1. Postmortem Inspection Results. Salmonella-suspected samples showed congestion and enlarged liver and spleen were enlarged, the two cecal cores were enlarged and contained caseated material, oviduct and ovaries were affected, fibrinous-perihepatitis, fibrinous-pericarditis, the kidney was congested and enlarged, and unabsorbed yolk sac was found in young chicks. E. coli-suspected samples showed omphalitis in newly hatched chicks, and the other ages had airsacculitis with turbidity in the air sac, enlarged liver and heart with fibrinous pericarditis and fibrinous perihepatitis, and congestion in the lung; in some cases, swollen head and salpingitis were found. Staphylococcus-suspected samples showed arthritis, swollen joints with a presence of yellow caseated material, femur head which may be separated from its shaft, and congestion in the internal organs; in some cases, the liver was enlarged and contained abscess.

3.2. Isolation, Identification, and Antibiotic Resistance. Salmonella was isolated from 128 out of 657 (19.5\%) examined farms which were examined in the period from 2014 to 2018. Table 1 and Figure 1 mention the number of positive farms which were examined every year. All Salmonella isolates were examined for antibiotic resistance against 10 different antibiotics (ampicillin, chloramphenicol, ciprofloxacin, doxycycline, levofloxacin, nalidixic acid, norfloxacin, penicillin, tetracycline, and trimethoprim). We found that the highest percentage of resistance was with penicillin and then ampicillin. All over the years, the percentage of resistance was high with chloramphenicol, ciprofloxacin, norfloxacin, tetracycline, and trimethoprim. The percentage of resistance against antibiotics is mentioned individually in Table 2 and Figure 2.

E. coli was isolated from 496 out of 657 (75.5\%) examined farms which were examined in the period from 2014 to 2018. Table 1 and Figure 1 mention the number of positive 
Table 1: Incidence of Salmonella, E. coli, and Staphylococcus isolated from poultry farms in the period 2014 to 2018.

\begin{tabular}{|c|c|c|c|c|c|c|}
\hline & \multicolumn{2}{|l|}{ Salmonella } & \multicolumn{2}{|l|}{ E. coli } & \multicolumn{2}{|l|}{ Staphylococcus } \\
\hline & No. of positive samples & $\%$ & No. of positive samples & $\%$ & No. of positive samples & $\%$ \\
\hline $2014(n=134)$ & 13 & 9.7 & 99 & 73.9 & 106 & 79.1 \\
\hline $2015(n=118)$ & 14 & 11.9 & 85 & 72 & 98 & 83 \\
\hline $2016(n=178)$ & 30 & 16.9 & 175 & 98.3 & 167 & 93.8 \\
\hline $2017(n=83)$ & 18 & 21.7 & 38 & 45.8 & 53 & 63.9 \\
\hline $2018(n=144)$ & 53 & 36.8 & 99 & 68.8 & 73 & 50.7 \\
\hline Total $(n=657)$ & 128 & 19.5 & 496 & 75.5 & 497 & 75.6 \\
\hline
\end{tabular}

$n=$ total number of examined farms.

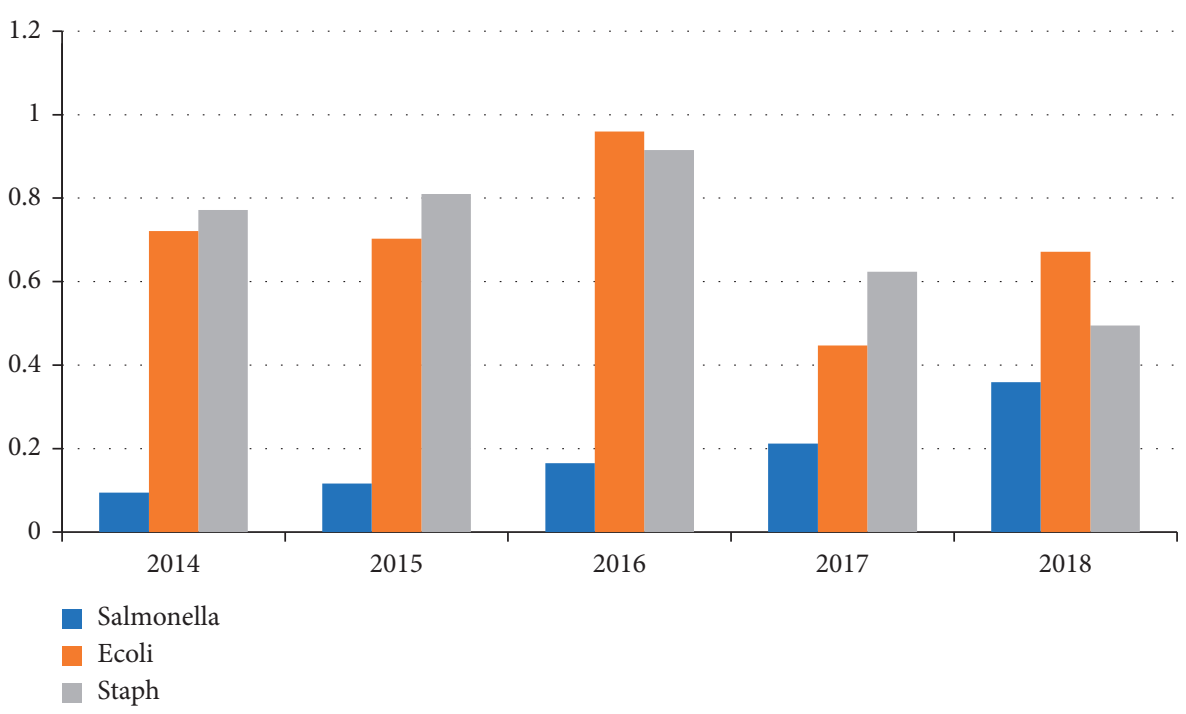

Figure 1: Incidence of Salmonella, E. coli, and Staphylococcus isolation from 2014 to 2018.

TABle 2: Antibiotic resistance profile of Salmonella isolates from 2014 to 2018.

\begin{tabular}{|c|c|c|c|c|c|c|}
\hline Antibiotics & $2014(n=13)$ & $2015(n=14)$ & $2016(n=30)$ & $2017(n=18)$ & $2018(n=53)$ & Total $(n=128)$ \\
\hline Ampicillin & $67 \%$ & $100 \%$ & $100 \%$ & $85 \%$ & $84 \%$ & $90.6 \%$ \\
\hline Chloramphenicol & $50 \%$ & $58 \%$ & $50 \%$ & $71.4 \%$ & $57 \%$ & $62.2 \%$ \\
\hline Ciprofloxacine & $20 \%$ & $61.5 \%$ & $33 \%$ & $50 \%$ & $68 \%$ & $52.3 \%$ \\
\hline Doxycycline & $50 \%$ & $92 \%$ & $50 \%$ & $47 \%$ & $81 \%$ & $70.7 \%$ \\
\hline Levofloxacine & $33 \%$ & $81 \%$ & $31 \%$ & $25 \%$ & $34 \%$ & $39.4 \%$ \\
\hline Nalidixic acid & $100 \%$ & $100 \%$ & $81 \%$ & $64 \%$ & $89.5 \%$ & $82.5 \%$ \\
\hline Norfloxacine & $33 \%$ & $50 \%$ & $55 \%$ & $43 \%$ & $65 \%$ & $53.2 \%$ \\
\hline Penicillin & $100 \%$ & $100 \%$ & $100 \%$ & $67 \%$ & $100 \%$ & $94.4 \%$ \\
\hline Tetracycline & $50 \%$ & $100 \%$ & $81 \%$ & $87 \%$ & $86.5 \%$ & $86.2 \%$ \\
\hline Trimethoprime & $50 \%$ & $77 \%$ & $74 \%$ & $64 \%$ & $87.5 \%$ & $78.2 \%$ \\
\hline
\end{tabular}

Total = total percentage of resistant strains all over five years; $n=$ number of positive samples.

farms every year. Over the period from 2014 to 2018, all positive isolates of $E$. coli were examined for antibiotic resistance against 14 different antibiotics (ampicillin, chloramphenicol, ciprofloxacin, danofloxacin, doxycycline, fosfomycin, levofloxacin, nalidixic acid, norfloxacin, penicillin, tetracycline, streptomycin, trimethoprim, and enrofloxacin). The highest percentage of resistance all over the years was observed in ampicillin, penicillin, tetracycline, nalidixic acid, streptomycin, and trimethoprim, followed by fosfomycin, doxycycline, and also danofloxacin. The percentage of resistance against antibiotics is mentioned individually in Table 3 and Figure 3.
Staphylococcus was isolated from 497 out of 657 (75.6\%) examined farms which were examined in the period from 2014 to 2018. Table 1 and Figure 1 mention the number of positive farms isolated every year. Over the period from 2014 to 2018, all positive isolates for Staphylococcus species were examined for antibiotic resistance against 14 different antibiotics (ampicillin, chloramphenicol, ciprofloxacin, doxycycline, fosfomycin, levofloxacin, nalidixic acid, norfloxacin, nitrofurantoin, penicillin, streptomycin, tetracycline, trimethoprim, and enrofloxacin). The highest percentage of resistance all over the years was observed in tetracycline, streptomycin, ampicillin, and nalidixic acid followed by 


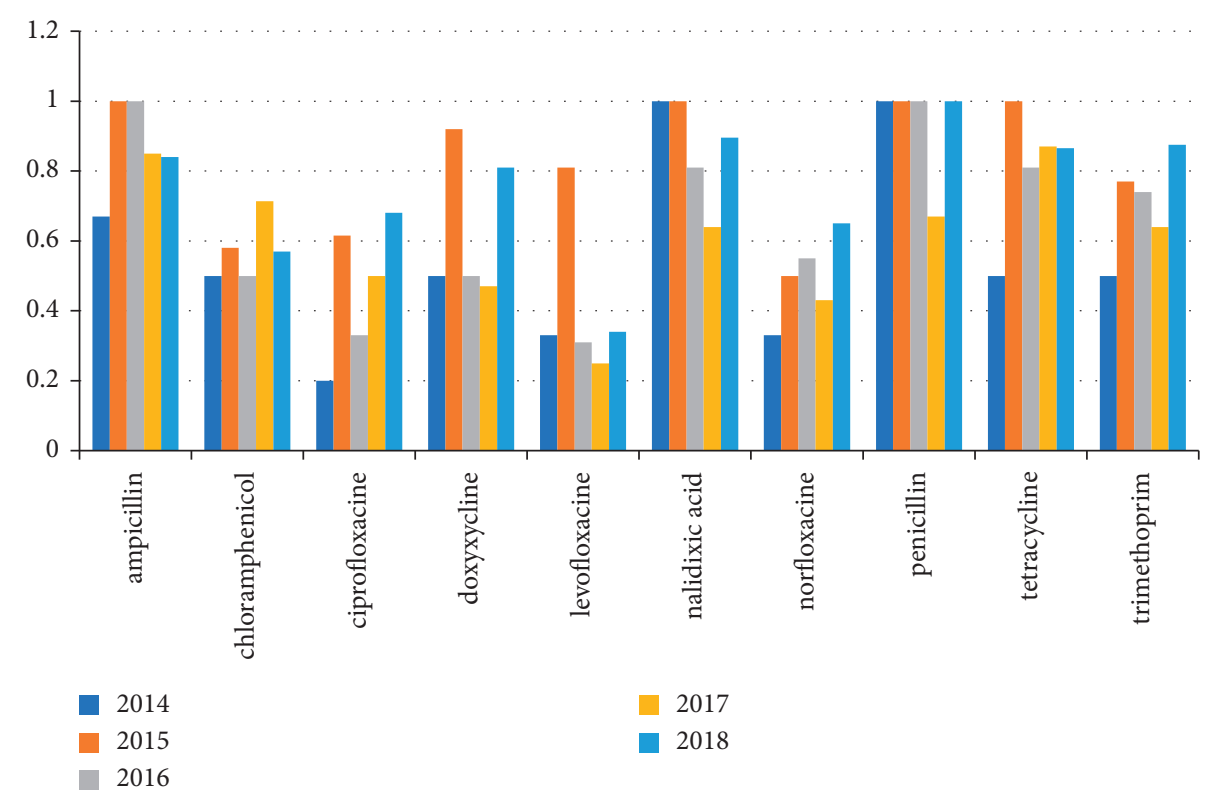

Figure 2: Antibiotic resistance profile of Salmonella isolates from 2014 to 2018.

Table 3: Antibiotic resistance profile of E. coli isolates from 2014 to 2018.

\begin{tabular}{|c|c|c|c|c|c|c|}
\hline Antibiotics & $2014(n=99)$ & $2015(n=85)$ & $2016(n=175)$ & $2017(n=38)$ & $2018(n=99)$ & Total $(n=496)$ \\
\hline Ampicillin & $94 \%$ & $96.5 \%$ & $99 \%$ & $100 \%$ & $95 \%$ & $97.2 \%$ \\
\hline Chloramphenicol & $74 \%$ & $71.4 \%$ & $83 \%$ & $80 \%$ & $78 \%$ & $78.4 \%$ \\
\hline Ciprofloxacine & $46 \%$ & $71 \%$ & $77 \%$ & $87.5 \%$ & $76 \%$ & $71 \%$ \\
\hline Danofloxacin & $91 \%$ & $100 \%$ & $100 \%$ & $100 \%$ & $79.5 \%$ & $84.3 \%$ \\
\hline Doxycycline & $83 \%$ & $90 \%$ & $87.5 \%$ & $60 \%$ & $91 \%$ & $85.5 \%$ \\
\hline Fosfomycine & $95 \%$ & $40 \%$ & $100 \%$ & $100 \%$ & $84 \%$ & $85.5 \%$ \\
\hline Levofloxacine & $74 \%$ & $68 \%$ & $69 \%$ & $62.5 \%$ & $71 \%$ & $69.7 \%$ \\
\hline Nalidixic acid & $87 \%$ & $100 \%$ & $91 \%$ & $88 \%$ & $93.5 \%$ & $92 \%$ \\
\hline Norfloxacine & $83 \%$ & $68.5 \%$ & $78 \%$ & $77 \%$ & $86 \%$ & $77.3 \%$ \\
\hline Penicillin & $83 \%$ & $100 \%$ & $100 \%$ & $100 \%$ & $100 \%$ & $95 \%$ \\
\hline Streptomycin & $100 \%$ & $82.8 \%$ & $96.5 \%$ & $58 \%$ & $96.5 \%$ & $89.6 \%$ \\
\hline Tetracycline & $91 \%$ & $91.4 \%$ & $99 \%$ & $93 \%$ & $89 \%$ & $93.4 \%$ \\
\hline Trimethoprime & $91 \%$ & $87.2 \%$ & $83.5 \%$ & $84 \%$ & $88 \%$ & $86 \%$ \\
\hline Enrofloxacine & $91 \%$ & $80 \%$ & $80 \%$ & $64 \%$ & $86 \%$ & $82.4 \%$ \\
\hline
\end{tabular}

Total $=$ total percentage of resistant strains all over five years; $n=$ number of positive samples.

penicillin, doxycycline, fosfomycin, trimethoprim, and chloramphenicol. The percentage of resistance against antibiotics is mentioned individually in Table 4 and Figure 4.

\section{Discussion}

The major problem nowadays all over the world in poultry production is infection with multidrug-resistant bacteria. The resistance to existing antimicrobials is widespread and of concern to poultry veterinarians because the administration of antimicrobials to chickens as therapeutic and subtherapeutic levels has been an integral part of poultry production. The practice of using unsusceptible antibiotics to the bacteria strain or using the antibiotics in low doses as growth promoters in poultry dietary plays a role in encouraging antibiotic-resistant organisms. Once established, resistant organisms can spread from farms to humans through the consumption of contaminated food [16]. In this study, we monitor some antibiotics and their effect on three major bacterial strains (Salmonella, E. coli, and Staphylococcus) which affect our poultry farms in the period from 2014 to 2018. Salmonellosis is one of the major bacterial diseases which affects the productivity of poultry farms, and we found an increase of Salmonella infection over the five years; also, Witkowska et al. [17] found an increase of Salmonella infection in 2015 and 2016 poultry farms. Also, Salmonella, E. coli, and Staphylococcus play a role in human foodborne illness due to the consumption of poultry infected with these microorganisms if they contain antibiotic resistance genes or not [18-20].

4.1. Salmonella Species Isolates. In this study, Salmonella was isolated from 128 out of 657 (19.5\%) examined poultry farms in the period from 2014 to 2018 , and these results were nearly 


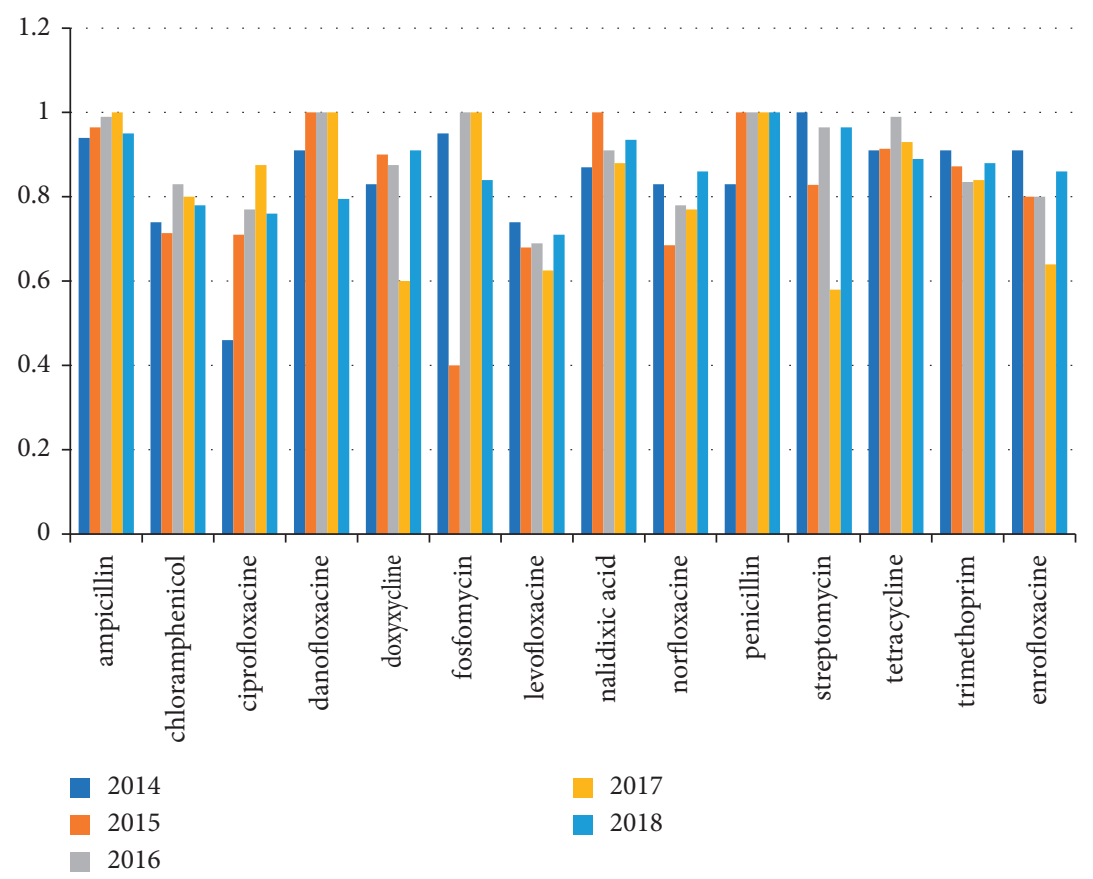

Figure 3: Antibiotic resistance profile of E. coli isolates from 2014 to 2018.

Table 4: Antibiotic resistance profile of Staphylococcus isolates from 2014 to 2018.

\begin{tabular}{|c|c|c|c|c|c|c|}
\hline Antibiotics & $2014(n=106)$ & $2015(n=98)$ & $2016(n=167)$ & $2017(n=53)$ & $2018(n=73)$ & Total $(n=497)$ \\
\hline Ampicillin & $52 \%$ & $100 \%$ & $96 \%$ & $90 \%$ & $92 \%$ & $91.6 \%$ \\
\hline Chloramphenicol & $76 \%$ & $80 \%$ & $79 \%$ & $78 \%$ & $88.4 \%$ & $80.6 \%$ \\
\hline Ciprofloxacine & $28 \%$ & $55 \%$ & $74 \%$ & $66 \%$ & $87 \%$ & $60.4 \%$ \\
\hline Doxycycline & $46 \%$ & $93 \%$ & $91 \%$ & $87.5 \%$ & $90 \%$ & $85 \%$ \\
\hline Fosfomycine & $94 \%$ & $25 \%$ & $100 \%$ & $67 \%$ & $85 \%$ & $83.1 \%$ \\
\hline Levofloxacine & $77 \%$ & $54 \%$ & $59 \%$ & $61 \%$ & $67 \%$ & $60.8 \%$ \\
\hline Nalidixic acid & $94 \%$ & $100 \%$ & $100 \%$ & $92 \%$ & $75 \%$ & $90.3 \%$ \\
\hline Norfloxacine & $71 \%$ & $58 \%$ & $59 \%$ & $59 \%$ & $61.5 \%$ & $60 \%$ \\
\hline Nitroforantine & $77 \%$ & $81 \%$ & $77 \%$ & $67 \%$ & $63 \%$ & $74.1 \%$ \\
\hline Penicillin & $43 \%$ & $95 \%$ & $95 \%$ & $92 \%$ & $97 \%$ & $87 \%$ \\
\hline Streptomycin & $94 \%$ & $96 \%$ & $91 \%$ & $100 \%$ & $93 \%$ & $92.9 \%$ \\
\hline Tetracycline & $71 \%$ & $97.5 \%$ & $93 \%$ & $95 \%$ & $98 \%$ & $93 \%$ \\
\hline Trimethoprim & $77 \%$ & $85 \%$ & $77 \%$ & $68 \%$ & $95.5 \%$ & $81.3 \%$ \\
\hline Enrofloxacine & $53 \%$ & $71 \%$ & $100 \%$ & $76 \%$ & $88 \%$ & $72.7 \%$ \\
\hline
\end{tabular}

Total $=$ total percentage of resistant strains all over five years; $n=$ number of positive samples.

average percentage to what Ammar et al. [21, 22] observed, who found Salmonella in examined poultry farms in Egypt in their study by $17 \%$ and $16 \%$, respectively. On the contrary, Badr et al. and Shehata et al. $[18,23]$ found Salmonella in low percentage, about $7 \%$ and $7.1 \%$, respectively, in samples isolated from poultry farms in Egypt. Moreover, El-Sharkawy et al. [24] isolated Salmonella in high percentage (41\%) from poultry farms in Egypt; also, Salmonella was isolated from poultry farms in Brazil and USA in high percentage, about $37 \%$ and $56 \%$, respectively $[25,26]$. In our study, in the period from 2014 to 2018, all positive samples for Salmonella were examined for antibiotic resistance against 10 different antibiotics which showed that the highest average percentage of resistance was with penicillin and ampicillin followed by tetracycline, nalidixic acid, trimethoprim, doxycycline, and chloramphenicol (94.4, 90.6, 86.2, 82.5, $78.2,70.7$, and $62.2 \%$, respectively). Subsequently, the percentage of resistance was decreased in norfloxacin, ciprofloxacin, and levofloxacin (53.2, 52.3, and 39.4\%, respectively). Also, Egypt [23] recorded that most of the tested Salmonella serovars were multidrug resistant and had high MAR indicated against the commonly used antibiotics in the poultry industry in Egypt. The data showed that $94.4 \%$, $72.2 \%, 44.4 \%, 44.4 \%, 33.3 \%$, and $33.3 \%$ of the tested Salmonellae were resistant to ampicillin, sulphamethoxazole/ trimethoprim, tetracycline, chloramphenicol, doxycycline, and norfloxacin, respectively. Moreover, Hassan et al. [27] revealed that Salmonella isolates showed complete resistance against penicillin, while they were highly resistant to nalidixic acid (80.8\%), sulphamethoxazole/trimethoprim 


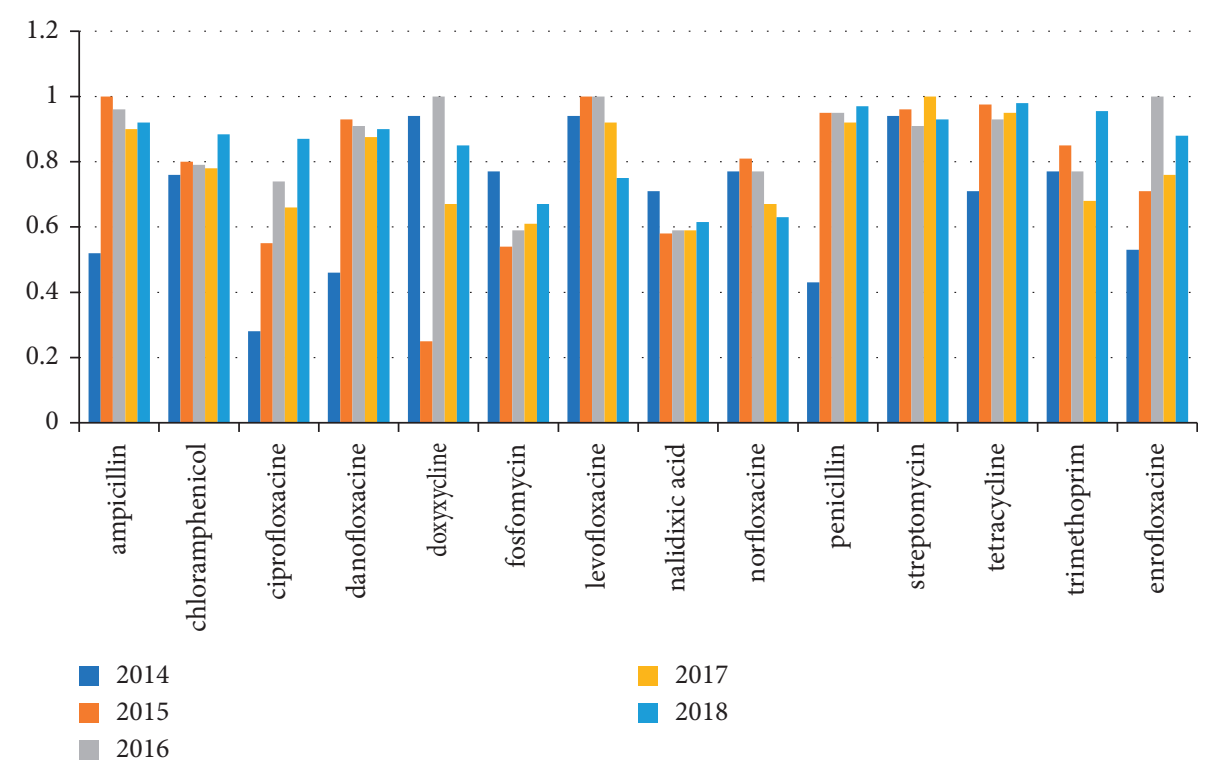

Figure 4: Antibiotic resistance profile of Staphylococcus isolates from 2014 to 2018.

(76.9\%), ampicillin (69.2\%), and oxytetracycline (65.4\%), while Eguale [28] reported that $42.3 \%$ were resistant to ampicillin and chloramphenicol, while 30.9\%, 19\%, 7.7\%, and $3.9 \%$ were resistant to tetracycline, nalidixic acid, ciprofloxacin, and trimethoprim for Salmonella isolated from broilers in Ethiopia. In contrast, Wang et al. [26], in USA, mentioned the rates of isolates resistant to ciprofloxacin and tetracycline (100\%), then chloramphenicol (99\%), ampicillin (97\%), and trimethoprim-sulfamethoxazole (97\%).

4.2. E. coli Isolates. In our study, we detected E. coli in 496 out of $657(75.5 \%)$ poultry farms examined in the period from 2014 to 2018; these chickens suffered from colibacillosis, and symptoms perihepatitis, pericarditis, airsacculitis, and omphalitis were found in postmortem examination; these results were near to what Stella et al. and Davis et al. $[29,30]$ observed who found that the percentage of $E$. coli was high, about $60 \%$ and $88 \%$ of examined chicken samples in Brazil and the USA, respectively, while AmeenUr-Rashid et al. and Ibrahim et al. [31, 32] found E. coli in low percentage, about $35.3 \%$ and $34 \%$ of examined chicken samples in Pakistan and Jordan, respectively. All E. coli strains isolated in the period from 2014 to 2018 were examined for antibiotic resistance against 14 different antibiotics and showed that there was high resistance all over the five years which ranged from $97.3 \%$ to $63.5 \%$, and these results agreed with Ibrahim et al., Jahantigh et al., and Rafiqueet et al. [33-35] who found the highest percentage of resistance to ampicillin, ciprofloxacin, doxycycline, nalidixic acid, streptomycin, tetracycline, and trimethoprim in Egypt, Iran, and Pakistan, respectively, and disagreed with what Ameen-Ur-Rashid et al. and Ibrahim et al. [31, 33] observed who examined the resistance of $E$. coli to the antibiotics and found low percentages to ampicillin, ciprofloxacin, chloramphenicol, doxycycline, enrofloxacin, norfloxacin, levofloxacin, and trimethoprim which ranged from $9 \%$ to $50 \%$ in Pakistan and Egypt, respectively.

4.3. Staphylococcus Isolates. In this study, Staphylococcus species were detected in 497 out of 567 (75.6\%) examined poultry farms in the period from 2014 to 2018, and the samples taken from these farms mostly suffered from affected joints, congestion in internal organs, and abscess in the liver, and these results were nearly the same to what Mariam-Shokery et al. [36] observed who found Staphylococcus species in $69.23 \%$ of infected examined chicken farms, while Amen et al. [20] found Staphylococcus species in $24.75 \%$ of examined chicken farms. All Staphylococcus isolates in the period from 2014 to 2018 were examined for antibiotic resistance against 14 antibiotics, and our results reported high resistance against tetracycline, streptomycin, ampicillin, and nalidixic acid, followed by penicillin, doxycycline, trimethoprim, and chloramphenicol all over the five years, and these results were the same to those mentioned in studies of other countries such as Indonesia, Pakistan, South Africa, and Nigeria [8, 37-39], respectively, while the results of tetracycline and chloramphenicol detected in [8] and the results of ampicillin, ciprofloxacin, enrofloxacin, and streptomycin examined in [20] were lower than what we found in our study.

\section{Conclusions}

This result indicates that the Salmonella infection in poultry has been dramatically increased annually with severe economic loss. It may be due to focusing on viral diseases such as AI (avian influenza), especially after AI outbreak in 2006 in Egypt at the expense of bacterial diseases in poultry.

Year 2016 shows a higher incidence of isolation of E. coli and Staphylococcus from poultry farms than in other years. 
This study shows an increase in the percentage of resistance in some antibiotics such as levofloxacin, norfloxacin, doxycycline, penicillin, tetracycline, and trimethoprim during the period from 2014 to 2018 in examined microbes (Salmonella, E. coli, and Staphylococcus), while still, Salmonella strains have moderate resistance to quinolones all over the five years. This increasing percentage of these antibiotics indicates the negative feedback of misuse of these antibiotics in poultry farms which act as a mirror of this misusage.

Misuse of antibiotics as unspecific treatment or as growth promoters may enhance generations of antibiotic resistance genes in bacteria which may infect poultry farms and may lead to high cost of treatment of infected farms due to the lack of antibiotics that can be used to treat multidrugresistant bacteria, as well as it can affect human health.

We recommend not to use antibiotics as growth promoters, must make antibiotic sensitivity test for infected farms before giving any antibiotics as treatment, and must take in our mind the withdrawal time of used antibiotics to protect human health. We must look for other ways to treat the microbial infection such as the use of natural products which have antimicrobial activity like essential oils, and the implementation of biosafety and biosecurity measures in poultry farms.

\section{Data Availability}

Samples were submitted to the Reference Laboratory for Veterinary Quality Control on Poultry Production for bacterial diseases' examination and sensitivity test for specific antibiotics.

\section{Conflicts of Interest}

The authors declare that they have no conflicts of interest.

\section{References}

[1] M. D. Mund, U. H. Khan, U. Tahir, B.-E. Mustafa, and A. Fayyaz, "Antimicrobial drug residue in poultry product and implications on public health; a review," International Journal of Food Properties, vol. 20, no. 7, pp. 1433-1446, 2017.

[2] E. Peterson and P. Kaur, "Antibiotic resistance mechanisms in bacteria: relationships between resistance determinants of antibiotic producers, environmental bacteria, and clinical pathogens," Frontiers in Microbiology, vol. 9, p. 1, Article ID 2928, 2018.

[3] A. Singh, D. Chhabra, R. Sharda et al., "Antibiotic resistance in E. coli isolated from," Poultry international journal of current Microbiology of applied science, vol. 8, no. 10, pp. 89-94, 2019.

[4] R. K. Gast, J. R. Glisson, L. R. McDougald, L. K. Nolan, D. L. Suarez, and V. Nair, "Editorial board for the American association of avian pathologists," Chapter 16 Salmonella infection, Blackwell Publishing, Hoboken, NJ, USA, 13th edition, 2013.

[5] L. K. Nolan, H. J. Barnes, J.-P. Vaillancourt et al., "Editorial board for the American association of avian pathologists," in Chapter 18 Colibacillosis, Blackwell Publishing, Hoboken, NJ, USA, 13th edition, 2013.
[6] C. B. Andreasen, D. E. Swayne, and J. Glisson, "Editorial board for the American association of avian pathologists," in Chapter 23 Other Bacterial Diseases (Staphylococcosis), Blackwell Publishing, Hoboken, NJ, USA, 13th edition, 2013.

[7] F. Abunna, M. Bedasa, T. Beyene, D. Ayana, B. Mamo, and R. Duguma, "Salmonella: isolation and antimicrobial susceptibility tests on isolates collected from poultry farms in and around Modjo, Central Oromia, and Ethiopia," Journal of Animal and Poultry Sciences, vol. 5, no. 2, pp. 21-35, 2017.

[8] J. Awogbemi, M. Adeyeye, and E. O. Akinkunmi, "A survey of Antimicrobial agents usage in poultry farms and Antibiotic resistance in Escherichia coli and Staphylococci isolated from the poultry in Ile-lfe, Nigeria," Journal of infectious diseases and Epidemiology, vol. 4, no. 1, p. 1, 2018.

[9] J. R. Middleton, W. H. Fales, C. D. Luby et al., "Surveillance of Staphylococcus aureus in veterinary teaching hospitals," Journal of Clinical Microbiology, vol. 43, no. 6, pp. 2916-2919, 2005.

[10] International Standards Organization, ISO 6579 Microbiology of Food and Animal Feeding Stuffs-Horizontal Method for the Detection of Salmonella, International Standards Organization, Geneva, Switzerland, 2002.

[11] International Standards Organization, ISO 6579-1 (en) Microbiology of the Food Chain-Horizontal Method for the Detection, Enumeration and Serotyping of Salmonella-Part 1: Detection of Salmonella spp, International Standards Organization, Geneva, Switzerland, 2017.

[12] M. D. Lee, K. L. Nolan, D. Zavala et al., "Editorial board for the american association of avian pathologists," A Laboratory Manual for the Isolation and Identification of Avian Pathogen Louis, Blackwell Publishing, Hoboken, NJ, USA, 5th edition, 2008.

[13] International Standards Organization ISO ISO 6888-1, Microbiology of Food and Animal Feeding Stuffs-Horizontal Method for Enumeration of Coagulase-Positive Staphylococci (Staphylococcus aureus and Other Species International Standards Organization ISO ISO 6888-1, Geneva, Switzerland, 2003.

[14] E. W. Koneman, S. D. Allen, and M. W. D'And, P. C. Soherchenberger and W. C. Winn, Colour Atlas and Text Book of Diagnostic Microbiology, Lippincott, Philadelphia, NY, New York, 5th edition, 1997.

[15] CLSI/NCClS, Performance Standards for Antimicrobial Disk Susceptibility Tests, CLSI, Wayne, PA, USA, 2013.

[16] H. Badr, M. A. Soliman, and S. A. Nasef, "Bacteriological and molecular study of Salmonella species associated with central nervous system manifestation in chicken flocks," Veterinary World, vol. 13, no. 10, pp. 2183-2190, 2020.

[17] D. Witkowska, M. Kuncewicz, J. P. Żebrowska, J. Sobczak, and J. Sowińska, "Prevalence of Salmonella spp. in broiler chicken flocks in northern Poland in 2014-2016," Journal of Annals of Agriculture and Environmental Medicine, vol. 25, no. 4, pp. 693-697, 2018.

[18] H. Badr, H. Roshdy, H. K. Sorour et al., "Phenotypic and genotypic characterization of Salmonella enterica serovars isolated from imported poultry," Journal Advanced Animal Veterinay Science, vol. 9, no. 5, pp. 1-11, 2021.

[19] A. Zhang, X. He, Y. Meng et al., "Antibiotic and disinfectant resistance of Escherichia coli isolated from retail meats in sichuan, China," Microbial Drug Resistance, vol. 22, no. 1, pp. 80-87, 2016.

[20] O. Amen, A. Hussein, R. Ibrahim, and R. S. Ibrahim, "Detection of antibiotics resistance genes in Staphylococcus aureus 
isolated from poultry farms," Assiut Veterinary Medical Journal, vol. 65, no. 163, pp. 1-9, 2019.

[21] A. M. Ammar, A. A. Mohamed, M. I. Abd El-Hamid, and M. M. El-Azzouny, "Virulence genotypes of clinical SalmonellaSerovars from broilers in Egypt," Journal of Infection in developing countries, vol. 10, no. 4, pp. 337-46, 2016.

[22] M. ElSheikh, E. Abdeen, and A. M. Ammar, "Molecular detection of some virulence genes of salmonella serotypes isolated frompoultry in Egypt," Journal of Current Veterinary Research, vol. 1, pp. 86-93, 2019.

[23] A. A. Shehata, S. Basiouni, A. A. Elrazk et al., "Characterization of salmonella enterica isolated from poultry hatcheries and commercial broiler chickens," Pakistan Veterinary Journal, vol. 39, no. 4, pp. 515-520, 2019.

[24] H. El-Sharkawy, A. Tahoun, A. A. El-Gohary et al., "Epidemiological, molecular characterization and antibiotic resistance of Salmonella enterica serovars isolated from chicken farms in Egypt," Gut Pathogens journal, vol. 9, Article ID 8, 12 pages, 2017.

[25] D. Voss-Rech, L. Potter, C. S. L. Vaz et al., "Antimicrobial resistance in nontyphoidal Salmonella isolated from human and poultry-related samples in Brazil: 20-year meta-Analysis," Foodborne Pathogens and disease, vol. 14, no. 2, pp. 116-124, 2016.

[26] J. Wang, H. Sheng, W. Xu et al., "Diversity of serotype, genotype, and antibiotic susceptibility of Salmonella prevalent in pickled ready-to-eat meat," Frontiers in Microbiology, vol. 10, p. 15, Article ID 2577, 2019.

[27] W. Hassan, A. Abed, A. E. R. Thabet, and E. Nady, "Genetic analysis of multidrug resistant Salmonella isolated from broiler chickens," Journal of Veterinary Medical Research, vol. 25, no. 1, pp. 121-131, 2018.

[28] T. Eguale, "Non-typhoidal Salmonella serovars in poultry farms in central Ethiopia: prevalence and antimicrobial resistance," BMC Veterinary Research, vol. 14, Article ID 217, 8 pages, 2018 .

[29] A. E. Stella, M. Cristina De Oliveira, V. L. D. da Silva Fontana, R. P. Maluta, C. A. Borges, and F. Antônio de Ávila, "Characterization and antimicrobial resistance patterns of Escherichia coli isolated from feces of healthy broiler chickens," Animal Pathology, vol. 83, p. 15, 2016.

[30] G. S. Davis, K. Waits, L. Nordstrom et al., "Antibiotic-resistant Escherichia coli from retail poultry meat with different antibiotic use claims," BMC Microbiology, vol. 18, Article ID 174, 2018.

[31] Ameen-Ur-Rashid, S. S. A. Shah, M. A. Khan, and A. Ali, "Isolation of Escherichia coli from poultry liver and it's Antibiogram profile," Research Journal for Veterinary Practitioners, vol. 5, no. 1, pp. 12-14, 2017.

[32] R. A. Ibrahim, T. L. Cryer, S. Q. Lafi, E. A. Basha, L. Good, and Y. H. Tarazi, "Identification of Escherichia coli from broiler chickens in Jordan, their antimicrobial resistance, gene characterization and the associated risk factors," BMC Veterinary Research, vol. 15, p. 16, Article ID 159, 2019.

[33] W. A. Ibrahim, S. A. Marouf, A. M. Erfan, S. A. Nasef, and J. K. ElJakee, "The occurrence of disinfectant and antibioticresistant genes in Escherichia coli isolated from chicken in Egypt," Veterinary World journal, vol. 12, no. 1, p. 145, 2019.

[34] M. Jahantigh, K. Samadi, R. E. Dizaji, and S. Salari, "Antimicrobial resistance and prevalence of Tetracycline resistance genes in Escherichia coli isolated from lesions of Colibacillosis in broiler chickens in Sistan, Iran," Journal of BMC Veterinary Research, vol. 6, pp. 1-6, Article ID 267, 2020.
[35] M. Rafique, R. F. Potter, A. Ferreiro et al., "Genomic characterization of antibiotic resistant Escherichia coli isolated from domestic chickens in Pakistan," Journal of Frontiers in Microbiology, vol. 10, pp. 1-10, Article ID 3052, 2020.

[36] H. M. Mariam-Shokery, I. A. H Redwan, W. A. Abd ElGhany, and M. M. Amer, "Molecular detection of antibiotics resistance genes in identified coagulase negative staphylococci from chicken flocks and hatcheries in Egypt," Egypt Journal of Veterinary Sciences, vol. 49, no. 1, p. 70, 2018.

[37] N. S. P. Hermana, Z. Nilasari, E. Yuniarti et al., "Antibiotic resistance profile of Staphylococcus aureus, Streptococcus spp. and Klebsiella spp. isolated from chicken farm in bogor, sukabumi, and cianjur, west java," Journal of Physics: Conference Series, vol. 18, pp. 1-6, 2020.

[38] M. A. Syed, H. Ullah, S. Tabassum et al., "Staphylococci in poultry intestines: a comparison between farmed and household chickens," Poultry Science, vol. 99, no. 9, pp. 4549-4557, 2020.

[39] C. C. Dweba, O. T. Zishiri, and M. E. El Zowalaty, "Isolation and molecular identification of virulence, Antimicrobial and Heavy metal resistance genes in livestock-associated methicillin-resistant Staphylococcus aureus," Pathogens, vol. 8, no. 79 , p. $21,2019$. 